\title{
High-Speed Rail for Central and Eastern European Countries: A Conference Report
}

\author{
Monika Jandová, Zdeněk Tomeš, ${ }^{1}$ Chris Nash ${ }^{2}$
}

\begin{abstract}
The European transport strategy promotes the role of railways and expects that the key role in passenger transport should be played by high-speed rail (HSR). Although the core network of high-speed lines has already been built and is operating in Western Europe, there has been little coverage so far in Central and Eastern Europe (CEE). The aim of the conference "High-Speed Rail for CEE Countries" that took place in Prague in June 2016 was to put together academics, policy-makers, and practitioners interested in HSR and to formulate recommendations for CEE countries based on West European countries' experience. Based on the conference presentations and subsequent discussion, the following conclusions were formulated. Firstly, there are many crucial differences in national HSR build-up and operation, which means that former experience of Western Europe is not directly applicable to CEE countries. Secondly, in comparing presentations discussing experiences in France, Britain, Italy, and Germany, it was concluded that the German approach-upgrading existing lines where possible and only building new lines for bottleneck sections - was the most likely appropriate solution in CEE. Lastly, CEE has the additional problem of many border crossings, with a reduction of traffic in comparison with purely domestic routes, and this effect has to be taken into account.
\end{abstract}

Key words: Central and Eastern Europe, demand forecast, ex-ante evaluations, economic geography, high-speed rail

JEL Classification: L92, L98, K23

\section{Introduction}

The conference "High-Speed Rail for CEE Countries" took place on 9-10 June 2016, in Prague. Participants from the Czech Republic, Great Britain, France, Italy, Germany, and Poland attended the conference and included academics, policy-makers, and practitioners.

\footnotetext{
${ }^{1}$ Katedra ekonomie, Ekonomicko-správní fakulta MU, Lipová 41a, 60200 Brno, jandova@econ.muni.cz; tomes@econ.muni.cz.

${ }^{2}$ Institute for Transport Studies (ITS), Lifton Villas, 1-3 Lifton Place, University of Leeds, C.A.Nash@its.leeds.ac.uk.
}

(C) 2016 by the authors; licensee Review of Economic Perspectives / Národohospodářský obzor, Masaryk University, Faculty of Economics and Administration, Brno, Czech Republic. This article is an open access article distributed under the terms and conditions of the Creative Commons Attribution 3.0 license, Attribution - Non Commercial - No Derivatives. 
Even if the Central European region offers opportunities for new high-speed rail (HSR) investment, it is necessary to take into account the fact that the construction of HSR is very capital-intensive and that the economic level of Central and Eastern European (CEE) countries is much lower than that of their Western European counterparts. Therefore, there is a question regarding where and when it is worth building HSR in the CEE countries. In response to this question, the following issues were discussed:

- Cost-benefit analysis of HSR projects.

- $\quad$ Ex-ante and ex-post evaluation of HSR projects.

- Estimations of current and future transport demand.

- Cost estimations of construction and operation of HSR.

- $\quad$ Experience with construction, operation, and financing of HSR.

- $\quad$ Potential HSR routes in the CEE countries.

- Geographical patterns of rail traffic flows in the CEE countries.

- Political aspects of HSR construction and operation.

\section{Presentations}

The conference day was split into three sessions. The first session consisted of presentations aimed mainly at general aspects of HSR building and experiences from France and Germany. The second session pointed at HSR experiences from Italy and Germany and was concluded with a presentation solving the question of whether (and potentially where) to build HSR in Central Europe. The third session continued with aspects of HSR potential in Poland and the Czech Republic.

\section{First session - General issues}

Professor Chris Nash (University of Leeds) opened the conference and was the conference keynote speaker. His presentation started by reviewing the general motivation behind HSR investment and, next, he focused on the costs and benefits of HSR and of how they are measured in cost-benefit analyses. Nash emphasised that the most important determinants of HSR economic success are construction costs (depending heavily on terrain and accessibility of city centres), level of timesavings, valuation of timesavings (much lower for business travellers than is commonly suggested; even lower in poor countries) and wider economic impacts.

Then, Nash presented examples of appraisals for French HSR, Madrid-Sevilla line, Madrid-Barcelona line and the UK - both ex ante and ex post. He highlighted the circumstances in which benefits may be expected to exceed costs and what alternatives should be considered (e.g. alternative routes, longer trains, upgrading existing lines etc.). Nash concluded that HSR is only justified when traffic volumes are expected to be high. Typically, HSR needs around 10 million passengers per annum density on social costbenefit terms and much higher density for commercial viability. On the other hand, construction costs and level of timesavings also are crucial. Where the above-mentioned aspects are not sufficient to justify HSR building, there is a space for revised pricing (i.e. a policy to damp down demand), upgrading existing lines, or building a new line for conventional speeds. 
The second speaker was Yves Crozet, who presented the French experience with HSR. He emphasised that HSR in France has 30 years of development and has become a national priority. HSR in France carries more passengers by far on its high-speed trains than any other European country at this time. Crozet raised the question of up to what extent new HSR lines can be opened in France. He claimed that it is necessary for developers to focus their projects on local needs and financial constraints as this will prevent France from a nightmare through the proliferation of structurally loss-making lines.

Next, he emphasised that the French model teaches us a basic lesson: that it is geography not economics that is the crucial factor. The key element for a high-speed line is optimal distance of between 400 and 1,000 km, sufficiently large centres of population justifying 15 to 20 return journeys per day, and a customer base with the means to pay. Therein, Crozet identified the key factors of HSR success in France: geography, the size of the cities and their distance (gravity model); economy, the demand and intensity of traffic; history and institutions, the monopoly of SNCF; technology; and, last but not least, politics. Finally, Crozet concluded with the idea that high speed has its place, but it should not be the default option. It is necessary to take into account the fact that there are a number of other ways of improving the rail offer. Before deciding which option is best, we should take the time to study each situation on its own merits.

The final speaker of the first session was Roger Vickerman, who focused on the impacts of HSR on regional economic development. He emphasised that HSR has differential impacts on different regions and within regions and there is a need to understand how changes from HSR affect the way businesses connect with each other and with labour markets. These effects include labour supply effects, the impact of increased density, the relocation of employment, and the impact on competition in imperfectly competitive markets as a result of improved accessibility. According to Vickerman, a cost-benefit analysis aimed at HSR raised many issues such as the question of forecasting longdistance trip-making over long periods and related assumptions about economic growth, about business and non-business travel behaviour, assumptions on fare structures and price elasticities, and values of in-vehicle time savings, especially in the case of business travel.

Vickerman concluded with the question of whether investment in HSR could change the regional balance of the economy. Conventional cost-benefit analysis is argued to have limitations in dealing with investments of this type. We should be aware of the fact that there are the outstanding issues as well. These issues include accessibility and connectivity and cities versus wider regions.

\section{Second conference session-Central Europe}

The second conference session was opened by Fabio Croccolo and his presentation dealing with the Italian experience with HSR. Croccolo started with Italian HSR and its main goals and development. The HSR network in Italy was planned with a view to linking the most densely populated and highly productive areas of Italy. It is also integrated into the old conventional network in order to maximise potential traffic more effectively. Based on the Italian experience, high-speed rail is competitive up to a distance of $1000 \mathrm{~km}$, provided that it is not interrupted by too many stops, otherwise opti- 
mal distances fall to between 500 and $700 \mathrm{~km}$ depending on the forecast operating speed. Simultaneously, it is essential to connect the most populous and important cities in the country in order to justify the investment and to achieve satisfactory socioeconomic returns.

Finally, Croccolo summarised the impacts of Italian HSR in three fields: mobility, freight, and environmental sensibility. First, in the case of mobility there was an increase of transport production, a reduction in journey time, and an increase in modal split. The new competitor on the HSR market has not had the effect of eroding the number of passengers carried by the incumbent. Consequently, HSR has shown that it can compete successfully with road and air transport and with conventional passenger rail services over medium-to-long-distance high-traffic routes. Croccolo closed his speech with the idea that a modern railway system is the greatest development opportunity for a country to increase mobility, logistics, and environmental sensibility and to guarantee new economical and social benefits.

The second presenting speaker of this session, Heike Link, presented German experiences with HSR construction and operation. First of all, she emphasised the polycentric settlement structure in Germany, which requires many stops, and the characteristics of HSR in Germany. There are not rays to centre in Germany as there are in France or Spain, nor is there line-structure as there is in Japan. Consequently, HSR in Germany is rather a network with many entry points, high train frequency, many stops, and low average speed. Link also mentioned that a specific feature of German HSR is that ICE trains (i.e. German high-speed trains) are rather perceived as a brand and serve parts of the network that are not constructed for high speeds. In Germany, the prevailing way is more to upgrade existing lines rather than to construct new ones.

Link also identified the reasons for costs overruns in cost-benefit analyses for the German HSR as being due to over-optimistic demand forecasts, underestimated costs (e.g. exclusion of tunnels, short construction times, and low buffers for geological risks), change of legal obligations, citizens' protests, difficult topographic and geological situations, and long planning and construction times. Link finished by saying that German high-speed lines are very costly due to mountainous areas and urbanised areas requiring noise protection, they are rather slow, and they are perceived more as a long-distance travel product with better quality and prestige.

The last speaker of the second session was Zdeněk Tomeš, who presented some possibilities and limits of HSR construction in Central Europe. The question raised was whether it is worth it to build up the HSR network among the cities of Central Europe and which connections have the highest potential. The analysis utilised ranking methodology that was used formerly to assess the potential of American and Spanish HSR networks where three main categories of variables were used to determine the value of a ranking index to score the corridors in order to evaluate their HSR potential (i.e. population size, economic vitality, and distance between origin and destination). The analysis included the 10 most important international and 10 most important national connections in Central Europe.

Tomeš concluded that, based on the authors' methodology, two prospective HSR projects for CEE countries have emerged: first, an international line (Berlin to Dresden to 
Prague to Brno to Wien to Bratislava to Gyor to Budapest); and second, a national network (Warsaw to Krakow/Katowice and Warsaw to Lodz to Wroclaw/Poznan). Tomeš emphasised that the advantage of the international line is connecting main agglomerations in the area; however, it crosses no less than four international borders and would have significant impact on traffic flows due to the border effect. On the other hand, the advantage of the Polish national network lies in the elimination of the border effect and also the Polish lowlands geography would decrease costs. However, the population size of Polish cities is much smaller than of the capital cities of the international line. Therefore, careful estimation of potential future demand and costs is needed on both projects to determine whether HSR is worth building.

\section{Third conference session - Poland and Czech Republic}

The third conference session was started by Jakub Taczanowski. He posed the question of whether construction of an HSR in a medium-sized Central-European country such as Poland is advisable in the context of the actual transport needs and the economic situation of the country and its railways. HSR projects would be a completely new challenge for the Polish State Railways (PKP) because the whole region of CEE countries is a place where HSR construction has not yet been launched. However many discussions are taking place and several projects are being presented, many of them full of purely political aspects. Taczanowski stressed that very high construction costs could block all other investments - not only in projected new lines (e.g. mainly connections with airports) but also maintenance of the existing network which would result in a further decrease in the role of rail transport in the country, in particular in peripheral areas. Simultaneously, Taczanowski was of the opinion that HSR in Poland should be taken into consideration as a long-term project to be launched after the existing railway network of the country is modernised and the role of rail transport stabilised.

Taczanowski concluded that it is very difficult to evaluate the advisability of constructing HSR in Poland because the potential opportunities are balanced by several significant threats and risks. Consequently, he advised concentrating on the existing network by developing its potential (e.g. modernisation to the maximum speed of $200 \mathrm{~km} / \mathrm{h}$ in the case of Warsaw-Poznań or fragments of the Warsaw-Gdańsk lines) and by purchase of modern rolling stock. In addition, he suggested that HSR might be advisable and feasible in the future but as an important element of the entire rail transport system of the country.

The final speaker was Jan Ilík, who presented HSR concepts for the Czech Republic and the CEE countries. He opened his speech with summarising the European-wide challenge and the national challenge (with a possibility of EU co-financing) for high-speed transport in the Czech Republic. He claimed that the Trans-European Transport Networks (TEN-T) revision has brought a brand new feature to CEE countries-dedicated high-speed lines as an integral part of the European transport network. The Czech Ministry of Transport introduced a modified concept of HSR for the Czech Republic called Rapid Services whose aim is to build new high-speed lines to substantially increase network capacity and market share in passenger and freight transport and to enable 
operations of a highly efficient network based on utilisation of high-speed and conventional lines.

Ilík concluded with the statement that modernisation of conventional trunk lines close to finalisation and a new long-lasting development programme is needed in the Czech Republic. The priority, he asserted, is to stay well connected, which means that the Ministry of Transport needs to follow neighbouring countries where the system already exists or is going to be developed.

\section{Conclusions}

In the final part of the conference, there was a discussion about crucial points of HSL potential in the CEE region. The participants agreed that a very important factor is the border effect because the CEE region consists of many small countries with frequent borders. The Western European HS systems were constructed as national systems and where international connections were constructed, the traffic flows usually stayed below ex-ante estimation. The strength of this border effect will have a crucial impact on HSR potential in the CEE region. The discussants agreed that further important issues include how to quantify wider economic effects and what operational model to choose for HS infrastructure.

Nash concluded the discussion with some comments. He mentioned that there are major differences between countries in terms of the major influences on their economic cases for HSR, in particular in terms of construction costs and values of time. Moreover, the case for HSR depends critically on the geography of the country or region- the size of the cities and the distance between them. The geography of CEE appears to be rather more like that of Germany than of France or Britain, with a number of medium-sized cities not too far apart rather than dominated by a single megacity. As a result, the German approach to HSR, namely upgrading existing lines wherever possible, but building new where there is an inevitable bottleneck in terms of capacity or where the practicality of upgrading for higher speeds exists, appears to be best for the region. In terms of the competitiveness of HSR, access charges for rail and road are an important issue; generally CEE has high access charges at present for conventional rail. Also, in an area where a large proportion of HSR trips will be international, it will be essential to have efficient through-ticketing and strong marketing of international services.

The last word came from Roger Vickerman. He said, "When it comes to HSL, there is a double-edged problem for CEE countries: small countries and lots of borders".

\section{Presentations}

CROCCOLO, F. HSR in Italy, experience so far and competition: a win-win game! Available at: http://www.itregep.cz/media/92134/croccolo.pdf.

CROZET, Y. High Speed Rail in France: from ex-ante to ex-post evaluations. Available at: http://www.itregep.cz/media/92126/crozet.ppt.

ILÍK, J. Shaping the future - new HSR concept for the Czech Republic and CEE. Available at: http://www.itregep.cz/media/92127/ilik_2016.ppt. 
LINK, H. German HSR Experience - too slow and too costly? Available at:

http://www.itregep.cz/media/92128/link_hsr_germany.ppt.

NASH, C. When to Invest in High Speed Rail? Available at:

http://www.itregep.cz/media/92129/nash_hsr__prague_nash.ppt.

TACZANOWSKI, J., KRÓL, M. High-speed Railway in Poland - a political playground or a real need? Available at:

http://www.itregep.cz/media/92131/taczanowski.pptx.

TOMEŠ, Z. JANDOVA M., SEIDENGLANZ, D. High Speed Rail for Central Europe? Available at: http://www.itregep.cz/media/92132/tomes.pptx.

VICKERMAN, R. Wider economic impacts - Can HSR rebalance regional economies? Available at: http://www.itregep.cz/media/92133/vickerman.pptx. 